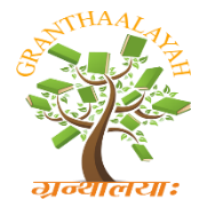

\author{
INTERNATIONAL JOURNAL OF RESEARCH - \\ GRANTHAALAYAH \\ A knowledge Repository
}

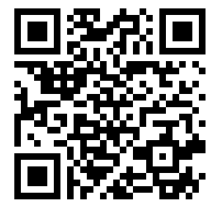

Social

\title{
SCIENTIFIC REASONING DEVELOPMENT WITHIN INFORMAL FORMATIVE ASSESSMENT USE IN SENIOR SECONDARY SCHOOL PHYSICAL SCIENCE LESSONS
}

\author{
Mzenzi S. Masuku ${ }^{1}$, Benson B. Simelane ${ }^{2}$ \\ ${ }^{1}$ Research Officer, Examinations Council of Swaziland, Research and Policy Development \\ Department, Swaziland \\ ${ }^{2}$ Science Teacher, Ngwane Park High School, Mathematics \& Science Department, Swaziland
}

\begin{abstract}
Scientific reasoning, though not explicitly taught in classrooms, is promoted as a major goal for Science, Technology, Engineering and Mathematics (STEM) education at all levels, worldwide. Literature also indicates that the time spent by learners explaining and justifying their ideas strongly correlates with learning improvement. In Swaziland, however, reports from school science inspectors and school leaving examiners point to weak evidence of scientific reasoning skills from school-based and high-stake examinations. This contradicts the main education goal at this level - producing learners who can use science phenomena awareness for reasoning through diverse life contexts. The study was conceived within the interplay between cognitive and sociocultural theories of constructivism. It focuses on how senior secondary school Physical Science teachers use informal formative assessment (IFA), and how the assessments so used support scientific reasoning. Through the qualitative inquiry approach a multiple case study design was used where four teachers in the Manzini Region were purposively sampled and their lessons observed. The data were then analysed through content analysis and Furtak, Harding, Beinbrech, Shavelson, and Shemwell (2008)'s analytical framework. The study revealed that teachers initiated learner-centred dialogues to address misconceptions and ask further clarification questions. Practical work and contingency based oral questions generated a reach variety of scientific reasoning levels while cases where teachers treated none response moments by supplying answers generated the least reasoning levels. All in all, by diligently using IFA to support learning, teachers realised opportunities for assisting learners migrate from concrete operational to formal thinking levels.
\end{abstract}

Keywords: Scientific Reasoning; Oral Questioning; Formative Assessment; Physical Science.

Cite This Article: Mzenzi S. Masuku, and Benson B. Simelane. (2019). "SCIENTIFIC REASONING DEVELOPMENT WITHIN INFORMAL FORMATIVE ASSESSMENT USE IN SENIOR SECONDARY SCHOOL PHYSICAL SCIENCE LESSONS." International Journal of Research - Granthaalayah, 7(6), 190-204. 10.29121/granthaalayah.v7.i6.2019.795. 


\section{Introduction}

Assessment is about questioning, something that can occur formally or informally. Most of informal assessment occurs formatively through classroom talk. Questions are a force that powers our thinking. What we say more often than not reflects what we think. Oral questions therefore make learners' thinking explicit and objective. Once learners' thinking is at such a state, it becomes useful data for the classroom teacher to examine and interpret for use in improving learning (Ruizprimo \& Furtak, 2007). When oral questioning is viewed from that angle it forms a major part of informal formative assessment.

Thinking can occur at different levels, one of which is critical thinking. Research has shown that higher order questions are more likely to develop critical thinking than lower order questions.

Critical thinking was coined by John Dewy as reflective thinking. As early as 1910 Dewey had defined this skill as an active, persistent and careful consideration of any belief in the light of the grounds that support it and the further conclusion to which it tends. This skill is needed in the school curriculum since it generates people with sound decision making, leadership and scientific judgement. Such competencies result in professional success and reflective participation in society (Kola, Rauscher, \& Haupt, 2019)

Literature has highlighted a number of sub-skills of critical thinking such as the ability to: ask questions, hypothesise, analyze, engage in scientific reasoning, and draw conclusions. Critical thinking as a solid competency becomes deficient if any one of its pillars is lacking. The lack of pillars such as scientific reasoning makes it hard for critical thinkers to interpret the evidence that emerges from their analysis of data. This then dampens the impact of critical thinking in that the thinking process never gets to decision making level without scientific reasoning.

Scientific reasoning (SR) is the process of coordinating fresh evidence with existing theory/knowledge (Sheir, Khalk, \& Babawy, 2015; Schumm \& Post, 1997).

In the science classroom before learners investigate a phenomenon, they declare a hypothesis which in ....'s view is a major sign of the beginning of critical thinking over a situation. This hypothesis is neither wrong nor right until suitably interpreted evidence proves it otherwise.

SR ability has a direct influence on the quality of problem-solving that individuals can perform in any area of life. As a result, it is generally promoted as a major goal of Science, Technology, Engineering and Mathematics (STEM) Education (Bao et al, 2009). The implication of the curriculum emphasis on SR is that the teaching of subjects like Science is changed from being straight forward empirical information to being a form of reasoning from evidence, a way of doing and thinking which actually involves higher-order thinking and evidence-based reasoning (Cope, 2013).

\subsection{Informal Formative Assessment}

Logically deployed oral questions have been found to be the best way by which educators stimulate learners' thinking (Henning, Renburg, \& Smit, 2004; Davoudi \& Sadeghi, 2015). This is of particular relevance at this time and age where contemporary approaches to learning emphasize the development of knowledge and understanding through talk and inquiry (Sampson \& 
Blanchard, 2012). These current views to learning argue for teaching that builds its pace and direction on the nature of learners' preconceptions and new information within an environment that promotes knowledge construction (Alexander, 2006). This teaching paradigm dictates that the teacher influences learning, by first interpreting how learners think and what shapes their thoughts (Brookhart, 2008). This learning precondition underscores the necessity of a means of instantaneously eliciting what learners have already learnt as the learning occurs. Such an assessment that occurs within the learning process with the purpose of improving learning is referred to as formative assessment (Black \& Wiliam, 2009). Formative assessment can either be formal, if planned beforehand, or informal if unplanned (Bell \& Cowie, 2001).

Informal Formative Assessment (IFA) in the classroom takes place when the teacher elicits thinking and makes immediate use of this knowledge in instruction (Ruiz-primo \& Furtak, 2007). It mainly consists of instructional dialogues which make learners' thinking explicit in an unobtrusive way. When learners' thinking is definite and clear, it can be examined, interrogated, and moulded as an object of constructive learning (Ruiz-Primo, 2011). With such a high number of informal assessments in the classroom context, how they are used and how they collectively affect learning and reasoning cannot be downplayed.

\subsection{Scientific Reasoning in Science Classrooms}

Reasoning occurs analogically whenever we compare new with old experience (Tajudin \& Chinnappan, 2017; Ibrahim, Ding, \& Stammen, 2016); it refers to logical thinking. Some scholars view it as the ability to separate and control variables from a given situation (Inhelder \& Piaget, 1958). Others regard it as the deliberate coordination of a claim with evidence (Ibrahim, Ding, \& Stammen, 2016; Furtak, Hardy, Beinbrech, Shavelson, \& Shemwell, 2008). SR is also referred to as the practice of thinking with and about scientific knowledge and involves coordinating claims with evidence (Cope, 2013; Kuhn, 2001). Bao et al (2009)'s regards it as a domain-general reasoning skill to systematically explore a problem, formulate and test hypotheses, manipulate and isolate variables, observe and evaluate the consequences. Despite their diverse views, these authors share a common view that SR is the mental ability of an individual to make claims based on a situation and coordinate them with findings from their systematic inquiry on the situation. A claim in this study shall be regarded as a subjective opinion freely chosen by the holder, such that its credibility improves with argument and evidence strength (Kuhn, 2001).

In a Chemistry lesson environment, scientific reasoning involves explanations of chemical phenomena, something that depends on the behaviour of sub-microscopic particles that are described using symbols, equations and diagrams (Chittleborough \& Treagust, 2007). The degree, therefore, to which learners can model particles, stands as a factor to their abilities to reason through Chemical concepts. By extension, any classroom intervention, that mitigates the effect of this factor, is likely to assist the learner's competence in explaining chemical phenomena. This ability then possibly adds value to learners' scientific reasoning ability.

Research from different contexts supports the fact that logical oral questioning has a positive impact on the development of learners' SR abilities (Sheir, Khalk, \& E.F, 2014; Davoudi \& Sadeghi, 2015). The impact of oral questioning on SR has also been investigated in China and Canada where positive correlation was established (Stiggins, Grisworld, \& Wikelund, 1989; Bao 
et al, 2009; Zimmerman, 2000). The sad part is that children are rarely asked questions that provoke critical thinking, and even where they are, only $15 \%$ of the teachers do. It was further noted that teachers can pose the original questions, they struggle with crafting follow up questions (Gillies, Nichols, Burgh, \& Haynes, 2014).

Gillies et al (2014) also investigated Grade 7 science learners, on the impact of higher order questioning against lower order questioning on SR and found that the impact of the latter was greater. It was also recommended that teachers need to model how to ask thought-provoking questions; to explicitly teach learners to ask and answer questions. The learners were then found to use analogies to verbally represent scientific concepts that underpinned their viewpoints.

Dutch teachers were found to address senior secondary science misconceptions from Dutch learners through explaining content in new ways, while clarifying explanations in response to classroom talk in the US were used to scaffold learners understanding of originally misconceived ideas (Kippers, Schildkamp, \& Poortman, 2016; Ruiz-Primo, 2011). In challenging teachercentred teaching, Shirley (2009) argued through a model that telling learners answers even if they had delayed responding, deprived them of thinking and remedial opportunities. The use of moments of contingencies through responding to learners' instantaneous responses to oral questions, was found to be more effective, particularly for teachers with a rich repertoire of teaching strategies (Shirley, 2009; Gamlem \& Munthe, 2014; Ruiz-primo \& Furtak, 2007)

Studies on the use of formative assessment in Swaziland have been carried out in Science and other disciplines by a variety of researchers, a few of which are cited (Masuku, Oloyede, \& Kelly, 2017; Dlamini, 2012; Kelly, 2007) These authors, though broadly focused on formative assessment as a whole, found that teachers informally assessed learners by probing the silence in cases of no response, rephrasing the question, providing hints and clues, repeating the questions, and slowing down the question pace.

Despite all these efforts to understand the impact of formative assessment, specifically IFA in the classroom, there has been no specific focus on how IFA influences learners' scientific reasoning abilities in those science classrooms. This has occurred at a time in the country where Physical Science teachers are still worried about how to teach and assess scientific reasoning (Marope, 2010).

Teacher trainers and school inspectors have for a while now, attempted to run special workshops in response to these classroom concerns. The feedback these teacher educators obtain from their workshops and inspection rounds, however, perpetually indicates that teachers fail to demonstrate competences that match their formal qualifications with regards to English proficiency, facilitation of learner-centred pedagogy, higher order thinking and problem-solving skills, assessment and lesson preparation. Over and above these worrying observations, the Swaziland General Certificate of Secondary Education (SGCSE) Physical Science examiners' reports over the past ten years have constantly highlighted a dearth in the evidence of logical reasoning from a majority of learners' responses to higher order items (ECESWA, 2008 - 2018). 


\subsection{Research Questions}

The current study, therefore, aims at assessing the extent to which informal formative assessment, in the form of classroom talk, affects scientific reasoning in senior secondary Physical Science classrooms. To achieve this goal we focused on two questions:

1) How do Physical Science teachers use informal formative assessment in their lessons?

2) To what extent do teachers use informal formative assessment to support scientific reasoning?

\subsection{Significance of the Study}

Scientific Reasoning ability has a positive effect on learning (Tajudin \& Chinnappan, 2017). If teachers and other curriculum implementation stakeholders are aware of the degree to which their oral questions support scientific reasoning, and ultimately effective learning, their prudence in deploying them would improve. Such impact carries the potential of overhauling the nature of the learning currently taking place in ESwatini Physical Science classrooms.

\subsection{Conceptual Framework}

There are several theories that explain how people learn. Major theories are those based on the behaviourist and on the constructivist paradigms. Constructivism as a learning theory argues that learners create meaning from external information in their own unique ways using their prior knowledge. In other words constructivism forms the basis of Posner (1982)'s model of dealing with misconceptions where the teacher is encouraged to create environments that establish firstly dissatisfaction with prior knowledge.

Posner (1982) further noted that the new concept must be intelligible, plausible and appear fruitful to the learner. In short Posner supports the literal creation of a cognitive conflict which subsides with the learners' realization of the strengths of the correct concepts and demerits of the misconception. When learners realise deficiencies in their original reasoning lines, they relinquish old inaccurate conceptions in favour of new ones. This can be achieved in Posner's view through group discussions that allow students to construct their own knowledge out of their friends and their teacher. Literature supports that oral discussions develop learners' abilities to think critically and to understand content (Bhim \& Aniruddha, 2013).

Scholars subscribing to constructivism are in two groups: cognitive and sociocultural constructivists. Piaget and Vygotsky are representatives of the former and latter, respectively.

Piaget through his developmental stage theory noted that children undergo the sensorimotor, preoperational, concrete operational and formal operational stages of growth in thinking. While the other stages involve younger children, this study's interest is on the concrete operational stage (involving 7-12 years) and the formal operational stage (involving children of 12 years upwards). The authors of this paper have deliberately avoided focusing only on the formal operational stage though the study's sample is on senior secondary school students who are already in the age ranges 16-18 years. Our deliberate stance to incorporate the concrete operational stage while excluding those stages that come earlier in life was because the thinking demanded by scientific reasoning at 
the SGCSE level, in Piaget's view begins to exist at the concrete operational stage. We also concur with the literature that Piaget made age proposals based on average mental abilities, but literature is strongly bringing up more evidence that very few people (25-33\% of gifted teenagers) reach the formal operational stage (Levine \& Linn, 1977; Arnett, 2010). Even those who do, they most likely have benefitted from any of the three factors: (a) maturation of their nervous systems; (b) favourable experiences within the physical environment; and (c) Exposure to favourable social environments such as schools (Inhelder \& Piaget, 1958)

Our understanding of the challenge faced with this study within Piaget's stage theory is that we know literature has confirmed that learners in the concrete operational stage can only achieve describing observed data from science investigations (Inhelder \& Piaget, 1958). We also know from literature that learners at the formal operational stage can reason beyond empirical data to describing patterns derived from the data. We thus understand the study's challenge to be establishing how teachers have taken advantage of informal formative assessments to assist learners at the concrete operational stage to begin to reason at the formal operational stage.

While our reasoning and argument has been on Piaget's lane of thinking, we are gradually becoming aware that informal formative assessments are social and dialogic by nature. They demand oral exchanges that employ language (a cultural tool) while actively engaging the learner's mind in thinking as they talk. This, in our view lands us on Vygotsky's territory of thinking which does not entirely demand that we preclude Piaget's views. As a matter of tact, though Piaget focused on internal mental processes' development, he never closed out the possibility that social dialogue also contributes positively to reasoning (Levine \& Linn, 1977). Vygotsky's main argument was that learning is not purely influenced by the strengths of the learner's mental processes - the influence of a more capable "adult" also counts. His argument is in line with Kuhn's assertion that group reasoning is superior to individual reasoning (Kuhn, 2001). The "adult" in the classroom context is either the teacher or the learner's peer. Our study then places interest in finding out how the teacher can take advantage of the teacher and peer dialogue opportunities to boost the learner's scientific reasoning ability. So our conception of the interplay of these factors in the classroom is summarised by the diagram below.

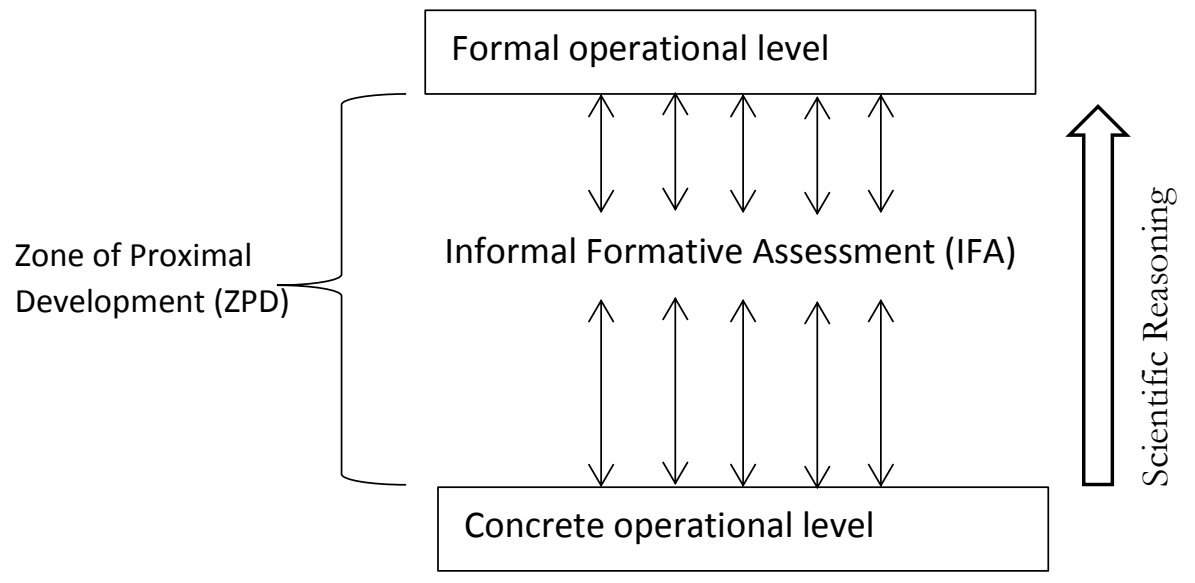

Figure 1: Conceptual diagram for scientific reasoning 


\section{Research Methodology}

This study was rooted on the qualitative inquiry approach. To answer the questions that guided the study, a multiple case study design was adopted. The population of this study was all Senior Secondary Physical Science teachers in Swaziland. Four teachers in the Manzini Region were purposively sampled on the basis of school-leaving certificate Physical Science results. These were teachers from the four best performing schools in the Manzini region. We felt the research area of monitoring the impact of classroom talk on learners' reasoning is under exploration and thus could best be tried out on best performing schools in the region. The Manzini region was also chosen because both researchers are resident in the area and are most likely to understand other factors outside the learner's classroom that may influence their scientific reasoning ability so that efforts to control them might be engaged. Typical examples are socio-economic factors such as coming from families and communities where the parents are actively involved in research.

\subsection{Research Instruments and Data Collection}

Lesson observations were conducted for each of the four schools on separate days during which descriptive notes were recorded in field notebooks as the lesson progressed. Predetermined research sub questions guided the research during the observation on where to pay much attention. The field notes were later-converted into computerised transcripts and consolidated with audio recording. Prior to observing the lesson, the researcher conducted pre-lesson interview to get a sense of the lesson organisation, learners' engagement during the lesson and the nature of planned learner activities. As soon as the lesson started the researcher turned on the audio recorder. The researcher took on a participant observer role during lesson observations. He also sat at the back of the class to minimise interference with lesson processes, and only moved around to probe learners reasoning_as they worked on group tasks or individual tasks through asking probing oral questions. Soon after observing the lesson the researcher held a brief talk with each of the participants to share experiences from their lessons. The teachers summarised their experiences by highlighting major lessons learnt from the lesson.

\subsection{Validity and Reliability}

The researcher then outlined the contents of the field notes and inquired if the record reflected what transpired during the lesson. Identified discrepancies were resolved by consensus. To achieve an inter-rater reliability, the co-researcher was then asked to read through the data and draw their own categories before researchers' categories were compared and areas of disparity resolved through a consensus.

\section{Data Analysis}

\subsection{Analysis of Use}

Transcripts of field notes were numbered line by line based on assessment moves made by both teacher and learner. An inductive content analysis approach was pursued beginning with reading through the data several times before creating categories of meaning. 


\subsection{Analysis of Impact of Use}

The Reasoning in Science Classroom Discourse Tool (Furtak, Hardy, Beinbrech, Shavelson, \& Shemwell, 2008) is meant for analysing transcribed than real-time classroom discourse. It was found appropriate for our data, where lessons were observed and data filed in transcribed form. It captures teachers' and students' co-constructed reasoning about science phenomena and quality of the backing for those claims. Claims that are supported by a rule are considered the most sophisticated, followed by those backed up by evidence (a summary of comparisons between data) and then those backed up by data (reference to observations), and lastly those claims with no backing at all. A reasoning unit in this framework refers to coherent segments of reasoning that refers to the same claim, premise or both.

Within each reasoning unit, three codes were applied: quality of reasoning, teacher's contribution and conceptual level. The quality of reasoning refers to the extent to which claims are backed up

with data, evidence and rules. The teacher's contribution speaks to the level of support the teacher provided during the unit through prompting for elements of reasoning or provided these themselves. The Conceptual level refers to the conceptual basis of claims being made.

\section{Unit of Analysis}

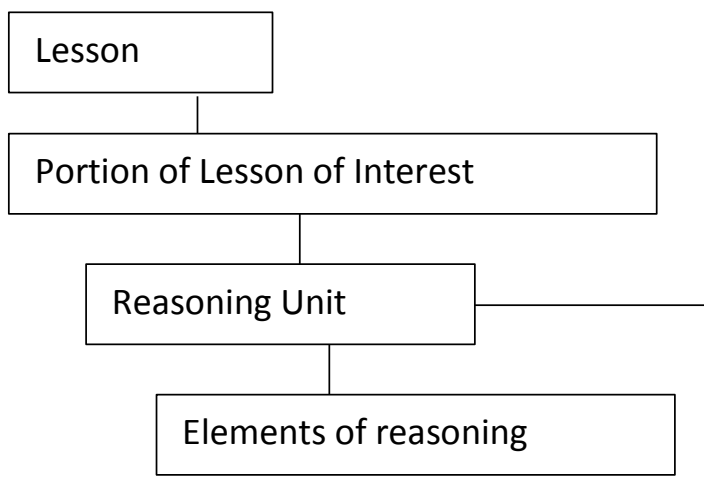

\section{Coding Category}

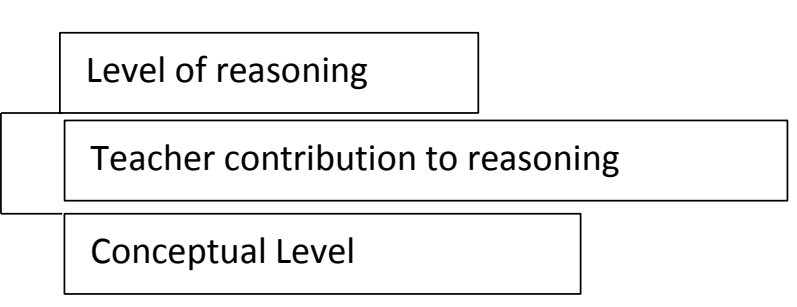

Figure 2: Furtak et al (2008)'s Coding Framework for Reasoning in Science Classroom Discourse

The table below represents the quality of reasoning in Science Classroom Discourse that was used to analyse the reasoning level achieved after teachers' application of informal formative assessment in their classrooms.

Table 1: Quality of Reasoning in Science Classroom Discourse

\begin{tabular}{|l|l|l|l|}
\hline $\begin{array}{l}\text { Reasoning } \\
\text { Level }\end{array}$ & $\begin{array}{l}\text { Quality of } \\
\text { Reasoning }\end{array}$ & Definition & Description \\
\hline $\mathbf{1}$ & Unsupported & No Reasoning & $\begin{array}{l}\text { Elements of reasoning present, but no } \\
\text { process of reasoning; pseudo, circular, or } \\
\text { tautological reasoning }\end{array}$ \\
\hline $\mathbf{2}$ & Phenomenological & $\begin{array}{l}\text { Data-based } \\
\text { reasoning }\end{array}$ & Data applied to claim \\
\hline
\end{tabular}


DOI: 10.5281/zenodo.3271547

\begin{tabular}{|l|l|l|l|}
\hline 3 & Relational & $\begin{array}{l}\text { Evidence-based } \\
\text { reasoning }\end{array}$ & $\begin{array}{l}\text { Evidence applied to a claim, including } \\
\text { the analysis of data }\end{array}$ \\
\hline 4 & Rule-based & $\begin{array}{l}\text { Inductive or } \\
\text { deductive rule- } \\
\text { based reasoning }\end{array}$ & $\begin{array}{l}\text { Deductive reasoning (top-down), } \\
\text { applying a rule to make a claim with } \\
\text { respect to a new premise } \\
\text { Inductive reasoning from data to rule } \\
\text { Applying a rule with new evidence } \\
\text { (exemplifying with analogy) } \\
\text { Complete reasoning structure (whole } \\
\text { framework) }\end{array}$ \\
\hline
\end{tabular}

\section{Results}

The characteristics of the teachers (T1, T2, T3 and T4) who participated in the study are summarised in the table below.

\begin{tabular}{|l|l|l|l|l|}
\hline Feature & T1 & T2 & T3 & T4 \\
\hline School location & Urban & Urban & Peri-Urban & Peri-Urban \\
\hline Qualifications & B.Ed. Sec. & B.Ed. Sec. & B.Sc. + PGDE & STD \\
\hline Classes taught & Form 4 and 5 & Form 4 and 5 & Form 4 and 5 & Form 4 and 5 \\
\hline Class size & 46 pupils & 33 pupils & 48 pupils & 40 pupils \\
\hline $\begin{array}{l}\text { Physical Science Teaching } \\
\text { Experience }\end{array}$ & 7 years & $\begin{array}{l}\text { At least 15 } \\
\text { years }\end{array}$ & $\begin{array}{l}\text { At least 15 } \\
\text { years }\end{array}$ & years \\
\hline SGCSE marking Experience & 5 years & None & None & 3 years \\
\hline
\end{tabular}

The table shows that half of the teachers taught at an urban school while the rest at a peri-urban school. T1 and T2 both had a Bachelor of Education in Secondary Science, while T3 had a Bachelor of Science and a Post Graduate Diploma in Education. T1 had the least teaching experience of 7 years yet highest (5 years) SGCSE marking experience among the four teachers. T2 and T3 had taught for at least 15 years and had no SGCSE marking experience. T4 had a Secondary Teachers Diploma in Education. While all four teachers taught both Form 4 and Form 5, their class sizes differed, ranging from 33 to 48 .

Research question 1: How do teachers use informal formative assessment during their lessons? The themes that emerged from the data corpus after the analysis indicated that teachers used informal formative assessment in five different ways: Recognition of prior knowledge, Scaffold prescription; Probing; Oral Evaluation and Treating own Question. The meaning of each theme is detailed below.

\subsection{Recognition of Prior Knowledge}

Recognition of prior knowledge happened at the beginning of the lesson during the review of the previous lesson. At this stage the teacher highlighted strengths and weaknesses within the learner' response and explained misunderstood content in fresh ways. Among these fresh ways were analogies and a series of illustrative examples. 


\subsection{Scaffold Prescription}

Teachers used scaffold prescription by passing oral remedial remarks on class presented homework. They did this by first allowing learners to present their work then asked the class to evaluate the presentation before the teacher asked a few oral questions (scaffolds) that supported the steps to the correct answer. The teachers demonstrated a deliberate reluctance to give the correct answer despite the implied desperation from the class. Sometimes the teacher gave incomplete statements for the learner to fill in the blanks orally. These hints appeared useful to learners as most ended up getting the answer right. In cases where learners took longer to get to the right answer, teachers told the learner the correct answer.

\subsection{Probing}

Teachers' probing was seen when they posed a further question soon after a response from the learner without passing an evaluative comment on the response. The teacher on the whole asked more questions after weak responses than after stronger responses since the nature of the questions were contingent to the quality of the response given by the learner. The sequencing of the question was more towards having the teacher understand the learner's reasoning line than to put the learners' weaknesses in the lime light.

\subsection{Oral Evaluation}

Oral evaluation at all levels of the lesson occurred when the teacher responded to learners' oral attempts by making short value judgements such as "good/bad", "yes/no" or invited the class for an applause.

\subsection{Treating Own Question}

The treatment of the teacher's own question was noticed as the teacher employed various ways of engaging learner in class activities after learners gave no response to a question. The teacher either rephrased his initial question or repeated the question at a lower pace or told learners the correct answer.

All in all, teachers from the four scenarios used IFA to orally address misconceptions that emerged as a result of diagnostic and intra-lesson questioning. This address took the form of probes that were logically based on learners' contingent responses, prescribed scaffolds such as oral "fill-inthe-blank" statements and as a last resort telling the learners the answer. There were also moments where value judgements were made on learners' attempts. In moments where the learner failed to make any attempt, the teacher either repeated or rephrased the question. In the worst case scenario where learners did not respond even after the adjustment of the original question, the teacher gave the entire answer to the learner.

Research question 2: To What Extent Did Teachers Use IFA to Support Scientific Reasoning? T1 taught a form four class where the aim of the lesson was to describe halogen reactivity trends. The lesson ran for an hour and twenty minutes. The table below summarises the data analysis outcome. 
Table 2: Summary of Codes from Teacher 1's Lesson Transcript by Reasoning Unit

\begin{tabular}{|c|c|c|c|}
\hline Unit & $\begin{array}{l}\text { Teacher Contribution to } \\
\text { Reasoning }\end{array}$ & Reasoning Level & Conceptual Codes \\
\hline 1 & $\begin{array}{l}\text { Teacher merely asked for halogen } \\
\text { definition. }\end{array}$ & Unsupported reasoning & $\begin{array}{l}\text { Claim was based on the } \\
\text { concept of halogen } \\
\text { definition }\end{array}$ \\
\hline 2 & $\begin{array}{l}\text { Teacher only prompted for the claim } \\
\text { Teacher also provided data that } \\
\text { completes the meaning of halogen. }\end{array}$ & Unsupported reasoning & $\begin{array}{l}\text { Definition/characteristics } \\
\text { of halogens }\end{array}$ \\
\hline 3 & $\begin{array}{l}\text { Teacher contribution to L1 } \\
\text { Reasoning } \\
\text { Teacher only prompted for the claim } \\
\text { Teacher then used L2 to provide the } \\
\text { answer to L1 } \\
\text { Teacher contribution to L2 } \\
\text { Reasoning } \\
\text { Teacher asked in general terms for a } \\
\text { backing: why do you think so? }\end{array}$ & $\begin{array}{l}\text { Quality of } L 1 \text { reasoning } \\
\text { Unsupported reasoning } \\
\text { Quality of L2 reasoning } \\
\text { L2 applied the rule of } \\
\text { reactivity increasing down } \\
\text { the group to predicting that } \\
\text { K will be more reactive } \\
\text { than Li. That was rule } \\
\text { based deductive reasoning. }\end{array}$ & $\begin{array}{l}\text { Learners were assisted to } \\
\text { reach more general ways } \\
\text { of predicting halogen } \\
\text { characteristics. }\end{array}$ \\
\hline
\end{tabular}

The table above shows that three of the four reasoning units yielded unsupported reasoning levels. In all these cases, the teacher through the introduction of halogen characteristics was prompting learners for a claim, which they gave but was never followed up. Where reasoning emerged in subsequent episodes, it was rule-based deductive reasoning that the teacher had prompted through a scaffold. This scaffold took the form of an incomplete statement hint and it was on halogen group trends.

The tabulated results of T2, T3 and T4 are only represented by summaries that were extracted from them. This was purely an effort to cut down on presentation monotony.

T2 taught a form 5 class where the aim of the lesson was to analyse the electrolysis of given electrolytes. Specifically the lesson sought to: (a) Name two states in which ionic compounds conduct electricity; (b) Compare and contrast the products of the electrolysis of sodium and copper (II) chloride solutions; (c) Write balanced half reactions for the electrolysis of molten Copper (II) Chloride.

Of the seven reasoning units within the lesson, two generated no reasoning, three data-based reasoning, one evidence based reasoning and three rule-based reasoning. This wide spectrum of reasoning levels was achieved through the teachers' prompts that took a variety of directions: (1) yes/no prompts that yielded no reasoning; teacher through the laboratory demonstrating requesting learners to tell what they observe than what they know which prompted for data-based reasoning; teacher requesting the learner to give a more complete response which generated an evidencebased reasoning level; Teacher probing for learner opinions and explanations of observed phenomena from the demonstration which led to both deductive and inductive rule-based reasoning levels. The teacher further used follow through questions to prompt learners to give an analogy from a newspaper scenario where the learnt rule applied. That analogy caused the learner to attain an inductive reasoning level. 
T3 taught a Form 5 class where the aim of the lesson was to compare and contrast covalent from ionic bonds. Specifically the lesson sought to: (a) Differentiate between an ionic and covalent bond; (b) Explain covalent bond formation. At the start of the lesson learners were asked to draw Lewis and Couper models of molecules on the green board. Of the five reasoning units within the lesson, one generated no reasoning, one data-based reasoning and three rule-based reasoning cycles. There were more rule based reasoning cycles that were produced and no evidence-based reasoning level was recorded. Within the rule-based reasoning cycles learners were able to achieve such through the teachers' probing for explanations to observed or declared claims. T3 also asked open ended questions to the learners and if they failed to respond he delayed telling them the answer and kept urging them to try harder.

T4 taught a Form 5 class where the aim of the lesson was to assist learners explain the kinetic theory. He first set up an apparatus of boiling water in a saucepan such that the lid flipped up and down under the influence of the steam. Learners were then asked to describe their observation, justify it, and explain why they thought their justifications were correct. Learners were further advised to split into three groups and each group was given a chance to present their answers to the class orally. The learners' responses varied slightly across the groups, but they generally ranged from data-based to rule-based reasoning depending on the probing level of the teacher. The first level of probing where learners were asked to explain the observation, most responses showed data-based reasoning levels that improved as the teacher made follow up remarks such as "Is that all; please elaborate". Better reasoning levels emerged as the teacher got to subsequent probes like asking learners to explain why they felt their responses were right.

In Summary the IFA method that involved contingently repeated cycles of questioning generated mainly rule-based reasoning. Yes/no or bad/good type of teacher evaluation of learner's attempts generated the least reasoning level. Lessons that were based on a laboratory demonstration or group presentations developed wider spectrums of SR levels.

\section{Findings and Discussion}

Teachers recognised prior learning through mentioning strengths and areas of improvement from learners' responses, and explained the misunderstood content in new ways. The practical demonstration with instructional dialogues that T2 used, for instance, led learners to drawing the desired conclusions on their own. This finding is consistent with Kippers, Schildkamp, and Poortman (2016)'s findings that indicated that teachers addressed misconceptions through explaining content in fresh ways. In addition, Ruiz-Primo (2011) found that offering explanations was one of the critical scaffolding strategies. In the current study T1 and T3's approaches to clarifying misconceived content were consistent with Ruiz-Primo's finding, but T2 achieved the same goal through a practical demonstration facilitated with dialogues, which is a more innovative approach than most conventional teaching methods.

Informal formative assessment was also used to attend to the teachers' initial questions. This occurred after learners failed to respond to the posed question. The teachers' responses involved telling the students the answer or repeating the question at the original or slower pace, and rephrasing the question. According to Ruiz-Primo (2011) rephrasing, clarifying, elaborating, summarising and repeating a question is a way of offering an explanation of what the question 
means, and it serves as a helpful scaffolding strategy. It can thus be inferred that by repeating and slowing down the question the teacher offered a way for learners to understand the question better.

Telling the students the answer in response to their silence, in the light of Shirley (2009)'s model, demonstrates a weak effort (as a matter of fact, no effort at all) to question learners for understanding, based on their engagement with an instructional task. Shirley (2009) then argues through her model that the teacher then fails to be aware of the learning need, which ultimately makes the selection and use of relevant teaching strategies impossible since there would be no information to base the strategy on. In the end no learning improvement occurs. It can thus be inferred that though repeating, slowing down or rephrasing a question symbolised good informal formative assessment practice, telling students the answer in response to their failure to respond to a question attracted no learning gain.

The prescription of a scaffold generally refers to the contigent teaching and learning that is motivated by the informal formative assessment outcome. The teachers in this study used oral explanations then made learners do assigned work such as corrections and consolidation classwork. Gamlem and Munthe (2014) uses the term "moments of contingencies" to describe the teachers' response at this stage of the learning process. Shirley (2009) argues that if this part is done from a rich repertoire of pedagogical strategies chances for improved learning are increased.

The teachers also probed learners reasoning through asking a further question when learners were expecting an evaluative feedback for their attempts. According to Ruiz-Primo and Furtak (2007) the informal formative assessment cycle involves the four stages commonly known as ESRU. By asking a further question the teachers had recognised the learner's response and used it to pose a further question. It is quite likely the teacher sought a deeper understanding of what the learner had understood and what they had not. In other words the teachers used informal formative assessment through the ESR-ESR... cycles instead of a single ESRU cycle.

The IFA method that involved contingently repeated cycles of questioning generated mainly rulebased reasoning. Yes/no or bad/good type of teacher evaluation of learner's attempts generated the least reasoning level. Lessons that were based on a laboratory demonstration or group presentations developed SR nearly at all reasoning levels. Class demonstrations that were interrogated between learners and teacher, appealed to both the sense of sight and hearing making concepts more stimulaing and clearer to the learner. This is consistent with sociocultural constructivism principles that peer-student-teacher discussions foster deeper learning since learners get a chance to help each other and also learn from their teachers (Vygotsky, 1978).

In the context of the current finding, where the teacher either purely probed or probed through a laboratory demonstration, higher reasoning levels emerged as a sign of the deep learning that had occurred (Furtak, Hardy, Beinbrech, Shavelson, \& Shemwell, 2008). This occurrence happens within the ZPD which serves the main need of all stakeholders of education - to have as many learners as possible begin to reason at the formal operational stage of Piaget's developmental stage theory. 


\section{Conclusion and Recommendations}

Learner-centred methods of using IFA were not only found to be in line with generally recommended uses of formative assessment, they also offered greater opportunity for learners to develop scientific reasoning at nearly all the levels. Practical-work-based and contingency probing generated a rich variety of SR levels and created greater opportunities for learners at the concrete operational level to be assisted to the formal operational level.

It is therefore recommended that the nature of resources that can effectively facilitate the implementation of learner centred pedagogies and promote practical work and group work in classrooms be made available to teachers. The knowledge and art of implementing such methods of teaching can be supported through in-service training.

\section{References}

[1] Alexander, R. (2006). Towards Dialogic Teaching: Rethinking Classroom Talk. Cambridge: Dialogos.

[2] Arnett, J. (2010). Adolescence and Emerging Adulthood: A Cultural Approach (3rd ed.). New York: Pearson.

[3] Bao et al. (2009). Learning and Scientific Reasoning. Science, 323, 586-587.

[4] Bell, B., \& Cowie, B. (2001). The Characteristics of Formative Assessment in Science Education. Science Education, 536-553.

[5] Bhim, C., \& Aniruddha, C. (2013). Misconceptions in Chemistry - Its Identification and Remedial Measures. Germany: Lap Lambert.

[6] Black, P., \& Wiliam, D. (2009). Developing the Theory of Formative Assessment. Educational Assessment, Evaluation and Accountability, 21, 5-31.

[7] Brookhart. (2008). How to give Effective Feedback to your Students. Alexandria, VA: Association of Supervision and Curriculum Development.

[8] Chittleborough, G., \& Treagust, D. (2007). The Modelling Ability of Non-Major Chemistry Students and their Understanding of the Sub-Atomic Level. Chemistry Education Research and Practice, 8(3), 274-292.

[9] Cope, B. (2013). Science in Writing: Learning Scientific Argument in Principle and Practice. ELearning and Digital Media, 420-441.

[10] Davoudi, M., \& Sadeghi, N. (2015). A Systematic Review of Research on Questioning as a Higher Level Cognition Strategy. English Language Teaching, 8(10), 76-90.

[11] Dlamini, M. (2012). Formative Assessment Practices of Secondary School History Teachers in Swaziland and Their Contribution to Learners Understanding. Kwaluseni: University of Swaziland.

[12] ECESWA. (2008 - 2018). SGCSE Physical Science Examiners' Report. Ezulwini: Ministry of Educatio and Training.

[13] Furtak, E., Hardy, I., Beinbrech, T., Shavelson, R., \& Shemwell, J. (2008). A Framework for Analysing Reasoning is Science Classroom Discourse. American Educational Research Association Conference (pp. 1-40). New York: AERA.

[14] Gamlem, S., \& Munthe, E. (2014). In Search of a Useful Definition of Mastery. Education Leadership, 19-23.

[15] Gillies, R., Nichols, K., Burgh, G., \& Haynes, M. (2014). Primary Students' Scientific Reasoning and Discourse During Cooperative Inquiry - Based Science Activities. International Journal of Educational Research, 63, 127-140. 
[16] Henning, E., Renburg, \& Smit. (2004). Finding Your Way in Qualitative Research. New York: Van Schaik.

[17] Ibrahim, B., Ding, L. M., \& Stammen, A. (2016). Scientific Reasoning: Theory Evidence Coordination in Physics-based and non - physics-based tasks. African Journal of Research in Mathematics, Science and Technology Education, 93-105.

[18] Inhelder, B., \& Piaget, J. (1958, June). The Growth of Logical Thinking: From Childhood to Adolescence. New York: Basic Books, Inc.

[19] Kelly, V. (2007). Alternative Assessment Strategies within a Context-based Science Teaching and Learning Approach in Secondary Schools in Swaziland. Cape Town: University of the Western Cape.

[20] Kippers, W., Schildkamp, K., \& Poortman, C. (2016). The Use of Formative Assessment by Teachers in Secondary Education in the Netherlands. Washington, DC: AERA.

[21] Kuhn, D. (2001). How Do People Know? Psychological Science, 12(1), 1-8.

[22] Levine, D., \& Linn, M. (1977). Scientific Reasoning Ability in Adolescence: Theoretical Viewpoints and Educational Implications. Advancing Eduation through Science-Oriented Programs. Journal of Research in Science Teaching, 1-38.

[23] Marope, M. (2010). The Education System in Swaziland - Training and Skills Development for Shared Growth and Competitiveness. Washington. DC: The World Bank.

[24] Masuku, M., Oloyede, O., \& Kelly, V. L. (2017). Teachers' Use of Formative Assessment in Senior Secondary School Chemistry Learning in Swaziland. Kwaluseni: University of Swaziland.

[25] Ruiz-Primo. (2011). Informal Formative Assessment: The role of instructional dialogues. Studies in Educational Evaluation, 15-24.

[26] Ruiz-primo, M., \& Furtak, E. (2007). Exploring Teaachers' Informal Formative Assessment practices and students' understanding in the context of Scientific Inquiry. Journal of Research in Science Teaching, 44(1), 57-84.

[27] Sampson, V., \& Blanchard, M. (2012). Science Teachers and Scientific Argumentation: Trends in Views and Practice. Journal of Research in Science Teaching, 49(9), 1122-1148.

[28] Schumm, J., \& Post, S. (1997). Executive Learning. Successful Strategies for College Reading and Studying. New Jersey: Prentice.

[29] Sheir, A., Khalk, V., \& Babawy, E. (2015). Oral Questioning Technique for Developing Critical Thinking Skills in EFL Classroom. Educational Sciences Journal, 1-23.

[30] Sheir, A., Khalk, W., \& E.F, N. (2014). Oral Questioning Technique for Developing Critical Thinking in EFL Classrooms. Educational Sciences Journal, 1-23.

[31] Shirley, M. (2009). A Model of Formative Assessment Practice in Secondary Science Classrooms Using and Audience Response System. Ohio: Ohio State University.

[32] Stiggins, R., Grisworld, M., \& Wikelund, K. (1989). Measuring Thinking Skills Throgh Classroom Assessment. Journal of Educational Measurement, 26(3), 1745-3984.

[33] Tajudin, N., \& Chinnappan, M. (2017). Relationship between Scientific Reasoning Skills and Mathematical Achievement Among Malaysian Students. International Journal of Contemporary Applied Sciences, 4(3), 107-123.

[34] Vygotsky, L. (1978). Mind in Society. Cambridge: Harvard University Press.

[35] Zimmerman, C. (2000). The Development of Scientific Reasoning Skills. Developmental Review, 20, 99-149.

\footnotetext{
*Corresponding author.
}

E-mail address: Masuku.s@ examscouncil.org.sz/ bhekibenson@ gmail.com 